\title{
A narrative review of sociodemographic risk and disparities in screening, diagnosis, treatment, and outcomes of the most common extrathoracic malignancies in the United States
}

\author{
Sarah Singh, Praveen Sridhar \\ Division of Thoracic Surgery, Department of Surgery, Boston University School of Medicine, Boston Medical Center, Boston, MA, USA \\ Contributions: (I) Conception and design: Both authors; (II) Administrative support: None; (III) Provision of study materials or patients: None; (IV) \\ Collection and assembly of data: None; (V) Data analysis and interpretation: None; (VI) Manuscript writing: Both authors; (VII) Final approval of \\ manuscript: Both authors. \\ Correspondence to: Praveen Sridhar, MD. Boston University School of Medicine, Surgical Education Office, 88 E. Newton Street, Collamore Building \\ Suite C-515, Boston, MA 02118, USA. Email: Praveen.Sridhar@bmc.org.
}

\begin{abstract}
There is a well-established association between multiple sociodemographic risk factors and disparities in cancer care. These risk factors include minority race and ethnicity, low socioeconomic status (SES) including low income and education level, non-English primary language, immigrant status, and residential segregation, and distance to facilities that deliver cancer care. As cancer care advances, existing disparities in screening, treatment, and outcomes have become more evident. Lung cancer remains the most common and fatal malignancy in the United States, with breast, colorectal, and prostate cancer being the three most common and deadly extrathoracic malignancies. Achieving the best outcomes for patients with these malignancies relies on strong physician-patient relationships leading to robust screening, early diagnosis, and early referral to facilities that can deliver multidisciplinary care and multimodal therapy. It is likely that challenges experienced in developing patient trust and understanding, providing access to screening, and building referral pipelines for definitive therapy in lung cancer care to vulnerable populations are paralleled by those in extrathoracic malignancies. Likewise, progress made in delivering optimal care to all patients across sociodemographic and geographic barriers can serve as a roadmap. Therefore, we provide a narrative review of current disparities in screening, treatment, and outcomes for patients with breast, prostate, and colorectal malignancies.
\end{abstract}

Keywords: Social determinants of health; cancer disparities; sociodemographic risk; screening disparities

Submitted Jan 13, 2021. Accepted for publication May 20, 2021.

doi: $10.21037 /$ jtd-21-87

View this article at: http://dx.doi.org/10.21037/jtd-21-87

\section{Introduction}

Lung cancer is both the most common and fatal malignancy among American men and women. Colorectal, breast, and prostate cancer remain the three most common and fatal extrathoracic malignancies (1). Precision medicine, a global term encompassing our ability to combine early diagnosis with safe application of surgery, radiation, endocrine, cytotoxic, and targeted molecular and immune therapies, has improved outcomes for those who can receive such comprehensive care (2-4).
Disparities in every phase of oncological care, from screening to delivery, have become evident among vulnerable populations $(1,5,6)$. These populations have been identified as high risk based on race, ethnicity, gender, socioeconomic status (SES), education status, immigrant status, primary language, place of work, access to care, and residential segregation, and distance from healthcare facilities, among other sociodemographic factors. As we look to address these disparities in patients with lung cancer, it is helpful to understand how sociodemographic risk has 
impacted care in common malignancies that similarly rely on screening and multimodal therapy for optimal outcomes. Here, we provide a narrative review and commentary of disparities that exist among vulnerable populations in breast, prostate, and colorectal cancer (CRC) outcomes, screening, diagnosis, management, and outcomes. We present the following article in accordance with the Narrative Review reporting checklist (available at: http://dx.doi.org/10.21037/ jtd-21-87).

\section{Methodology}

A literature search was performed using the MEDLINE PubMed catalog using a combination of keywords including "racial disparities", "ethnic disparities", "social determinants of health", "socioeconomic status", "primary language", "immigrant status", "screening disparities", "treatment disparities", "rural cancer care", "urban cancer care", "breast cancer", "colorectal cancer", and "prostate cancer". Full text articles written in the English language and published between the years 2000 and 2020 were subjectively assessed by the authors for content and relevance.

\section{Breast cancer}

Breast cancer is the most common-invasive cancer in women worldwide, affecting 1 in 7 women $(7,8)$. For women of average risk, the U.S. Preventive Services Task Force (USPSTF) and American College of Physicians (ACP) recommends mammography every two years in women between the ages of 50 and 74 (9). When diagnosed early, breast cancer is curable with a multimodal approach to therapy, even for cancers that have high risk molecular profiles. Advances in the application of endocrine and targeted therapies make the prospect of long-term disease control an increasing reality even in late stage disease (10). Risk stratification, however, extends beyond biology. Both biological and sociodemographic factors affect breast cancer outcomes, indicating the need to understand the impact of both sets of risk factors on outcome disparities (11). Table 1 summarizes the following sections in outcomes, screening, and treatment disparities in breast cancer care.

\section{Outcome disparities}

Multiple studies have shown higher rates of morbidity and mortality in breast cancer in vulnerable populations (12). Much of this data stems from population-based samples that have represent a substantial portion of the United States population. For example, one population-based study using the Surveillance, Epidemiology, and End Results (SEER) database and data provided by the North American Association of Cancer Registries (NAACR) of all women diagnosed with breast cancer between 2005 and 2017 showed that non-Hispanic Black (NHB) women have higher breast cancer mortality rates than non-Hispanic White (NHW) women, with rates as much as 39\% higher [mortality rate ratio (MRR), 1.39; 95\% confidence interval (CI), 1.35-1.43] in NHB women in 2015. These data represent a significant gap in survival and one that widened in the preceding half decade (2). The same study found that, from 2005 to 2014, overall breast cancer incidence increased yearly among Asian/Pacific Islander (1.7\% per year), NHB ( $0.4 \%$ per year), and Hispanic $(0.3 \%$ per year) women but were stable in NHW and American Indian/Alaska Native (AI/AN) women. Notably, breast cancer death rates were not significantly different in NHB and NHW women in 7 states (2). This may reflect either the existence of programs to ameliorate race-based survival disparities (e.g., mandatory insurance coverage), or more likely a lack of statistical power. Following Medicaid expansion, data from the Center for Disease Control and Prevention (CDC) was queried for survival disparities associated with race (13). There did not appear to be an association between state expansion of Medicaid and survival in breast cancer (13). This data demonstrates that the sheer existence of Medicaid expansion does not necessarily lessen survival disparities. However, a separate study by Abdelsattar et al. evinced that within the most disadvantaged populations, Medicaid coverage conferred a relative survival benefit over having no insurance (14).

With respect to racial and ethnic disparity, American Hispanics across all races have also been identified as a high-risk population, as they are more likely to be diagnosed at a younger age, have invasive cancer (compared to in situ disease), and triple negative disease relative to African American women. This is significant as Black women have already been identified as a vulnerable population (15). Interestingly, these racial disparities exist outside of the United States as well. A retrospective study aiming to identify associations between ethnicity and breast cancer survival in New Zealand found that Maori/Pacific women were at higher risk of excess mortality from breast cancer. Maori/Pacific patients were diagnosed at a younger age, with a higher burden of comorbidity, and were more likely to reside in lower SES neighborhoods. These women 
Table 1 A summary of studies examining disparities in screening, delivery, and outcomes in breast cancer care

\begin{tabular}{|c|c|c|c|c|c|}
\hline Study focus & Journal & Author and year & $\mathrm{N}$ & Study type & Summary \\
\hline \multirow{5}{*}{ Outcome } & Cancer Med & Nahleh et al. 2018 & 3,441 & $\begin{array}{l}\text { Retrospective } \\
\text { analysis of a multi- } \\
\text { institutional cohort }\end{array}$ & $\begin{array}{l}\text { - Hispanic Americans were more likely to be } \\
\text { diagnosed with breast cancer younger, have } \\
\text { invasive ductal carcinoma type }(82.7 \%) \text {, have } \\
\text { triple negative disease }(17.1 \%, 95 \% \mathrm{Cl}: 15 \% \\
\text { to } 19 \%) \text {, and have a higher prevalence of triple } \\
\text { negative disease compared to Black patients }\end{array}$ \\
\hline & BMC Cancer & Tin Tin et al. 2018 & 13,657 & $\begin{array}{l}\text { Retrospective } \\
\text { analysis of a health } \\
\text { region in New } \\
\text { Zealand }\end{array}$ & $\begin{array}{l}\text { - Maori women had a higher risk of excess } \\
\text { mortality from breast cancer (aHR 1.76, 95\% Cl: } \\
\text { 1.51-2.04 for Māori and 1.97, 95\% Cl: } 1.67-2.32 \\
\text { for Pacific women) }\end{array}$ \\
\hline & Cancer & $\begin{array}{l}\text { Abdelsattar et al. } \\
2016\end{array}$ & 134,105 & $\begin{array}{l}\text { Retrospective cohort } \\
\text { study of a national } \\
\text { database }\end{array}$ & $\begin{array}{l}\text { - Having insurance improved cancer-specific } \\
\text { survival the most in disadvantaged communities } \\
\text { (3 years, } 40 \% \text { vs. } 31 \%)\end{array}$ \\
\hline & Milbank Q & Silber et al. 2018 & 64,744 & $\begin{array}{l}\text { Retrospective cohort } \\
\text { study of a national } \\
\text { database }\end{array}$ & $\begin{array}{l}\text { - Low socioeconomic status patients were } \\
\text { diagnosed with more stage IV disease } \\
(P<0.0001) \text {, larger tumors }(P<0.0001) \text {, and lower } \\
\text { median survival }(P<0.0001)\end{array}$ \\
\hline & Cancer & Balazy et al. 2019 & 1,057 & $\begin{array}{l}\text { Retrospective cohort } \\
\text { analysis at a single } \\
\text { institution }\end{array}$ & $\begin{array}{l}\text { - Non-English speaking patients were significantly } \\
\text { more likely to present at advanced stage } \\
\text { compared to English speaking patients (OR 1.47, } \\
95 \% \mathrm{Cl} \text { : } 1.001-2.150, \mathrm{P}=0.0082 \text { ) }\end{array}$ \\
\hline \multirow[t]{3}{*}{ Screening } & Ann Surg Oncol & Newman et al. 2017 & $\mathrm{~N} / \mathrm{A}$ & Review & $\begin{array}{l}\text { - Frequency of breast cancer detected at Stage I } \\
\text { is more than } 10 \% \text { lower in Black and Hispanic } \\
\text { patients compared with White patients }\end{array}$ \\
\hline & $J$ Womens Health & Hirth et al. 2016 & 4,992 & $\begin{array}{l}\text { Cross-sectional } \\
\text { observational study }\end{array}$ & $\begin{array}{l}\text { - Higher income white women were more likely to } \\
\text { report having a mammogram (aPR 1.63, 95\% } \\
\text { Cl: 1.04-2.55) compared to lower income white } \\
\text { women }\end{array}$ \\
\hline & Am J of Surg & Simianu et al. 2016 & 6,286 & $\begin{array}{l}\text { Prospective cohort } \\
\text { study in Washington } \\
\text { State }\end{array}$ & $\begin{array}{l}\text { - Native Americans with breast cancer received } \\
\text { preoperative diagnostic core-needle biopsy less } \\
\text { frequently ( } 81 \% \text { vs. } 94 \%, \mathrm{P}=0.004) \text { and their } \\
\text { tumor's hormone receptor (ER/PR) status was } \\
\text { less frequently reported }(92 \% \text { vs. } 99 \%, \mathrm{P}=0.008) \\
\text { compared to non-Hispanic White women }\end{array}$ \\
\hline
\end{tabular}

Table 1 (continued) 
Table 1 (continued)

\begin{tabular}{|c|c|c|c|c|c|}
\hline Study focus & Journal & Author and year & $\mathrm{N}$ & Study type & Summary \\
\hline \multirow{3}{*}{ Treatment } & JAMA Surg & Lautner et al. 2015 & 727,927 & $\begin{array}{l}\text { Retrospective cohort } \\
\text { study of a national } \\
\text { database }\end{array}$ & $\begin{array}{l}\text { - Rates of breast conserving therapy were lower in } \\
\text { patients without insurance compared to private } \\
\text { insurance (OR } 0.75,95 \% \mathrm{Cl}: 0.72-0.78 \text { ) and } \\
\text { patients with the lowest income (OR } 0.92,95 \% \\
\mathrm{Cl}: 0.90-0.94)\end{array}$ \\
\hline & Cancer Epidemiol & $\begin{array}{l}\text { Akinyemiju et al. } \\
2016\end{array}$ & 67,000 & $\begin{array}{l}\text { Cross-sectional } \\
\text { observational study }\end{array}$ & $\begin{array}{l}\text { - Black patients were less likely to receive } \\
\text { mastectomies regardless of insurance status } \\
\text { (OR } 0.80,95 \% \mathrm{Cl}: 0.71-0.90 \text { ), and more likely to } \\
\text { experience post-surgical complications (OR } 1.41 \text {, } \\
95 \% \mathrm{Cl}: 1.12-1.78 \text { ). }\end{array}$ \\
\hline & Eur J Surg Oncol & Mets et al. 2018 & 1,045 & $\begin{array}{l}\text { Retrospective } \\
\text { analysis at a single } \\
\text { institution }\end{array}$ & $\begin{array}{l}\text { - Hispanic and Black patients had higher rates } \\
\text { of overall complications ( } 34.1 \% \text { vs. } 27.4 \% \text {, } \\
P=0.021) \text {; also with higher rates of neoadjuvant } \\
\text { chemotherapy ( } P=0.036) \text {, history of radiation } \\
\text { ( } P=0.016) \text {, were more likely to undergo modified } \\
\text { radical mastectomy ( } P=0.002) \text { over nipple- } \\
\text { sparing mastectomy }(P=0.035) \text {, and higher rates } \\
\text { of reconstructive complications }(P=0.023)\end{array}$ \\
\hline
\end{tabular}

were less likely to be diagnosed via screening, treated in a private care facility, receive timely treatment, and receive breast conserving surgery (16). This data suggests that sociodemographic risk confers similar and striking disparities in diagnosis and utilization of care globally.

SES has also been shown in several studies to be an independent risk factor associated with poor survival in patients with breast cancer. Using the SEER database, Silber et al. defined low SES using neighborhood poverty as well as education level and found a drastic decrease in survival for patients from low socioeconomic backgrounds compared to controls while accounting for treatment, stage at presentation, and other sociodemographic risk factors (17).

There is a paucity of data associating primary language and patients with non-English speaking backgrounds and outcomes in breast cancer. One single institution study from a quaternary care academic center demonstrated that non-
English speaking patients comprised of $15 \%$ of the total cohort and were more likely to present at later stages (18). A separate single institution study from an urban safetynet hospital over a similar time period found that just over $25 \%$ of patients were non-English speaking and did not experience any difference in mortality compared to English speaking patients. Furthermore, survival in this study was similar to national datasets (19).

\section{Screening and stage of presentation}

Currently, the USPSTF recommends mammography every two years in women between the ages of 50 and 74 (9). Unfortunately, disparities are evident in completion of screening mammography due to lower SES (including income, race, and ethnicity). Initial mammography utilization rates have been reported as similar for Black 
and White American women by the American Cancer Society at $68 \%$ and $71 \%$, respectively in the year 2000 ; however, repeat utilization of mammography is significantly lower for Black women than for White women (20). Despite the absence of large-magnitude variation initial mammography utilization, frequency of breast cancer detected at Stage I is more than 10\% lower in AAs and Hispanic Americans compared with White Americans (21). Hirth et al. highlighted that insurance coverage was associated with undergoing screening mammography only among White and Hispanic women (22). These authors additionally demonstrated the significance of SES with relation to receipt of screening mammography. In their cross-sectional study associating demographic data with screening mammography rates that White patients with a higher household income were more likely to report having a mammogram (aPR 1.63, 95\% CI: 1.04-2.55) compared to lower income White women (22).

While Black/White racial disparities are clear in breast cancer screening and diagnosis, there is limited data exploring disparities in other under-represented minority races $(2,23)$. Simianu et al. identified that American Indian/ Alaskan Native patients with breast cancer less frequently received preoperative diagnostic core-needle biopsy (81\% vs. 94\%) and their tumor's hormone receptor (ER/ PR) status was less frequently reported (92\% vs. 99\%), compared to NHW and other races. This dataset was limited to a Washington state registry of patients already receiving surgical care, and consequently may underestimate disparities in screening, diagnosis, and treatment though it does provide a possible mechanism by which delivery of standard of care therapies is not necessarily standard across demographic groups (23).

\section{Treatment}

The main avenues for current breast cancer therapy include endocrine, cytotoxic, targeted, and surgical therapy. The complexity of surgical decision making alone further allows for variable treatment patterns. While population-based studies have been valuable in identifying disparities in care, such studies are unable to capture granular data in this decision-making process.

Despite these limitations, current literature demonstrates that treatment based disparities still exist even in early stage surgical management of breast cancer (21). For example, Hoppe et al. evaluated persistent racial disparities in the treatment of stage 1 breast cancer patients and found that
Black women have longer times to first treatment, surgery, chemotherapy, radiation, and endocrine therapy than White women (24). A similar study conducted by Mets $e t a l$. characterized racial disparities among patients who receive breast mastectomy and reconstruction found that Hispanic and African American patients were more likely to undergo modified radical mastectomy $(\mathrm{P}=0.002)$ over nipple-sparing mastectomy $(\mathrm{P}=0.035)$ (12). Reconstructive complications revealed a higher overall complication rate $(\mathrm{P}=0.023)$, higher rates of partial mastectomy flap necrosis $(\mathrm{P}=0.043)$, as well as arterial $(\mathrm{P}=0.009)$ and venous insufficiency $(\mathrm{P}=0.026)$ during microvascular reconstruction among Hispanic and African American patients (12). Lautner et al. queried the National Cancer Database (NCDB) to assess the utilization of breast conserving surgery in patients with early stage disease and found that Medicaid-insured, uninsured, and low income patients less likely to undergo breast conservation therapy than privately insured and higher income patients (25). Additionally, Akinyemiju et al. assessed outcomes for patients undergoing inpatient treatment for breast cancer and similarly found lower rates of breast conserving surgery for Black patients as well as higher complication rates (26). Dreyer et al. examined the SEER database between the years 2006 and 2009 and stratified SES into quartiles based on poverty indices, per capita income, household incomes, and Medicaid insurance status. Poverty-stricken patients were less likely to undergo initial surgical management, nodal staging, and perioperative radiation and chemotherapy (27).

\section{CRC}

CRC is the third most common cancer and cause of cancer deaths in men and women in the United States (28). The USPSTF currently recommends that individuals at average risk start colorectal screening at the age of 50 with yearly stool-based tests and colonoscopies every 10 years until the age of 75 (29). With the advent of current screening guidelines, CRC mortality has improved markedly by improving early detection (3). The current therapeutic standard for CRC once diagnosed is dependent upon the stage of disease. Surgical resection with or without perioperative chemotherapy or radiation therapy is the only curative treatment modality for locoregional CRC (3). Despite global advances in both screening and therapy, there are vast disparities in diagnosis, treatment, and outcomes in CRC that are dependent upon sociodemographic risk factors. Table 2 summarizes the following sections in 
Table 2 A summary of studies examining disparities in screening, delivery, and outcomes in colorectal cancer care

\begin{tabular}{|c|c|c|c|c|c|}
\hline Study focus & Journal & Author and year & $\mathrm{N}$ & Study type & Summary \\
\hline \multirow{2}{*}{ Outcome } & Ann Surg Oncol & $\begin{array}{l}\text { Nitzkorski et al. } \\
2013\end{array}$ & 748 & $\begin{array}{l}\text { Retrospective study } \\
\text { of prospectively } \\
\text { maintained database }\end{array}$ & $\begin{array}{l}\text { - Median overall survival for all stages was } \\
\text { worse for nonwhite patients ( } 31 \text { vs. } \\
50 \text { months, } P<0.001 \text { ), and those with low } \\
\text { income and education }\end{array}$ \\
\hline & J Clin Oncol & $\begin{array}{l}\text { Robbins et al. } \\
2012\end{array}$ & $\mathrm{~N} / \mathrm{A}$ & $\begin{array}{l}\text { Retrospective } \\
\text { observational study } \\
\text { using national } \\
\text { database }\end{array}$ & $\begin{array}{l}\text { Between the } 1980 \text { s and } 2000 \text { s, CRC } \\
\text { mortality decreased for each stage in both } \\
\text { Black and White pts, but for all stages, the } \\
\text { decreases were smaller for Blacks }(P<0.01)\end{array}$ \\
\hline \multirow[t]{6}{*}{ Screening } & Am J Public Health & $\begin{array}{l}\text { Ahmed et al. } \\
2013\end{array}$ & 5,900 & $\begin{array}{l}\text { Cross-sectional } \\
\text { survey study }\end{array}$ & $\begin{array}{l}\text { - Compared with Whites, Hispanics were } 34 \% \\
\text { less likely }(P<0.01) \text { and Blacks were } 26 \% \\
\text { less likely }(P<0.05) \text { to receive } C R C \text { screening } \\
\text { and/or screening recommendations }\end{array}$ \\
\hline & $\begin{array}{l}J \text { Racial Ethn Health } \\
\text { Disparities }\end{array}$ & $\begin{array}{l}\text { Mobley et al. } \\
2017\end{array}$ & 558,568 & $\begin{array}{l}\text { Retrospective } \\
\text { observational study } \\
\text { using national } \\
\text { database }\end{array}$ & $\begin{array}{l}\text { - African-Americans, Hispanics, and Asians } \\
\text { were more likely to be diagnosed at a late } \\
\text { stage for } C R C \text { or both than whites in many } \\
\text { states }(P<0.05)\end{array}$ \\
\hline & $J$ Community Health & $\begin{array}{l}\text { Nagelhout et al. } \\
2017\end{array}$ & 197 & $\begin{array}{l}\text { Cross-sectional } \\
\text { observational study }\end{array}$ & $\begin{array}{l}\text { - After adjusting for age and gender, Hispanic } \\
\text { patients were less likely to report having } \\
\text { discussed } \mathrm{CRC} \text { screening options compared } \\
\text { to White patients }(\mathrm{OR}=0.24,95 \% \mathrm{Cl} \text { : } \\
0.09-0.68, \mathrm{P}<0.05)\end{array}$ \\
\hline & $J$ Community Health & Chan et al. 2016 & 311 & $\begin{array}{l}\text { Retrospective analysis } \\
\text { of a single institution } \\
\text { cohort }\end{array}$ & $\begin{array}{l}\text { - Blacks were significantly more likely to have } \\
\text { advanced stage CRC [3-4] at diagnosis } \\
\text { compared to Whites (OR } 3.70,95 \% \mathrm{Cl} \text { : } \\
0.97-14.11, \mathrm{P}=0.055)\end{array}$ \\
\hline & Cancer & $\begin{array}{l}\text { Brawarsky et al. } \\
2013\end{array}$ & 6,986 & $\begin{array}{l}\text { Retrospective } \\
\text { observational study } \\
\text { using national } \\
\text { database }\end{array}$ & $\begin{array}{l}\text { - Blacks were less likely than Whites to } \\
\text { undergo colonoscopy (OR } 0.76,95 \% \mathrm{Cl} \text { : } \\
0.69-0.83 \text { ) and to receive CEA testing and } \\
\text { overall surveillance }\end{array}$ \\
\hline & Am J Surg & $\begin{array}{l}\text { Carmichael et al. } \\
2019\end{array}$ & 486,303 & $\begin{array}{l}\text { Retrospective } \\
\text { observational study } \\
\text { using national } \\
\text { database }\end{array}$ & $\begin{array}{l}\text { - Highest screening rate states had the smallest } \\
\text { urban-rural disparities while lowest screening } \\
\text { rate states had the largest disparities }(74.6 \% \\
\text { vs. } 73.0 \%, 1.6 \% \text { difference vs. } 1.3 \% \text { vs. } \\
56.9 \%, 4.4 \% \text { difference) }\end{array}$ \\
\hline
\end{tabular}

Table 2 (continued) 
Table 2 (continued)

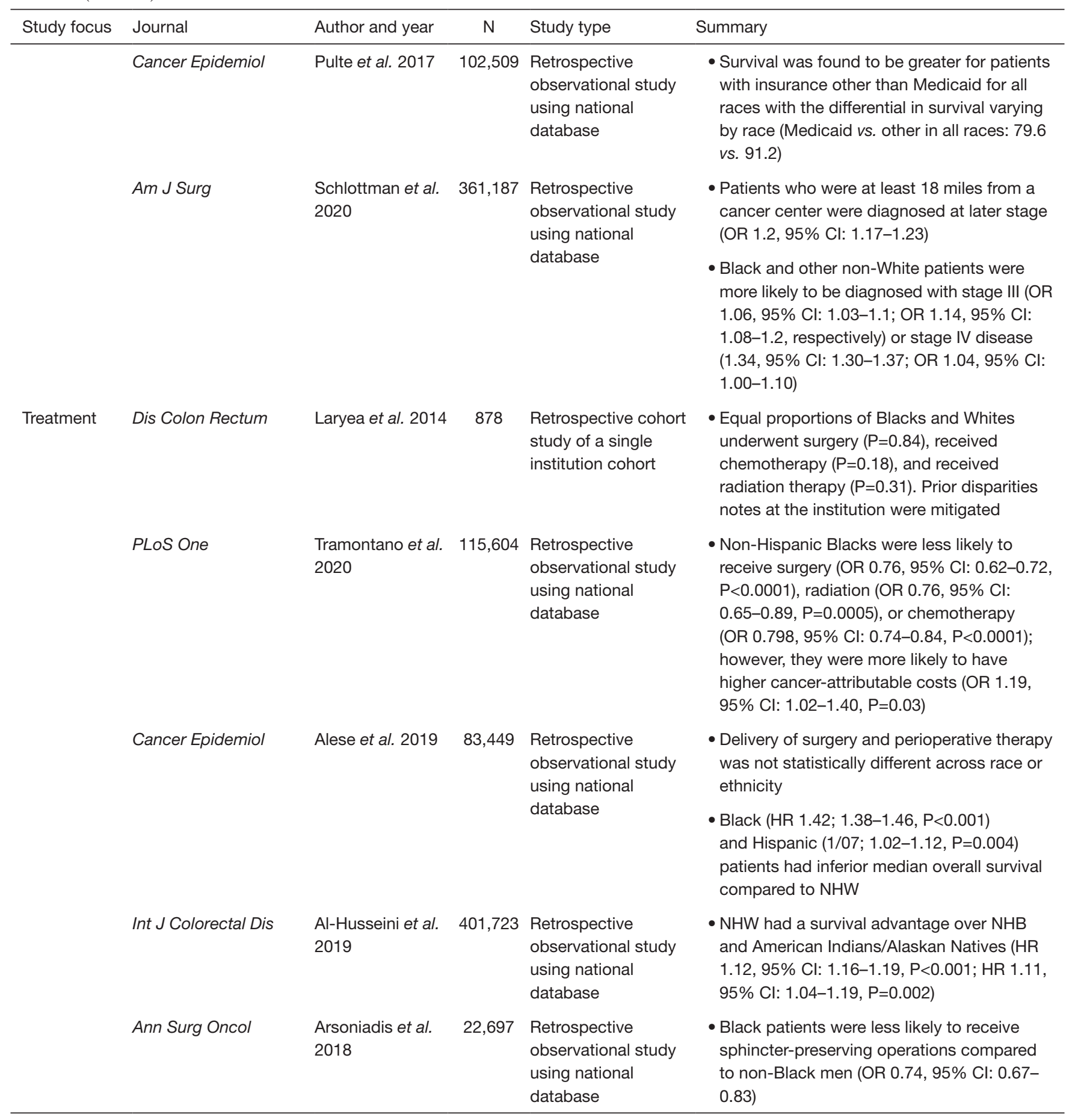


outcomes, screening, and treatment disparities in CRC care.

\section{Outcome disparities}

Numerous studies have outlined racial/ethnic differences in outcomes for CRC survival. It has been well documented in population based studies that non-Hispanic Black men and women have the highest of CRC-related incidence and mortality (30). Investigators have tried to elucidate mechanisms for increased CRC-related mortality in Black and Hispanic patients, with some studies concluding that medical comorbidities and SES may be important contributing factors (31). A study by Nitzkorski et al. to evaluate racial and socioeconomic disparities in outcomes of patients with rectal cancer found that the median overall survival for all stages is worse for nonwhite patients, those with low income, and those with low education with disparities being most pronounced for those with advanced stage disease (32). Although CRC mortality has decreased as a whole, the improvement in survival has not been experienced equally among all races. A study conducted by Robbins et al. using the SEER database found that between 1985 and 2005, stage-for-stage mortality decreased, but to a lesser degree for Black patients compared to White. Again, this finding was most prominent in late stage disease where mortality rates accounted for $60 \%$ of the overall disparity in mortality (33). Though notable, this may reflect differences in decision making for patients with late-stage disease, rather than differences in access, availability, or efficacy of care itself. However, even at safety net hospitals with presumably greater accessibility to vulnerable populations, Black patients experienced a lower likelihood of survival compared to White patients [median overall survival of 1.9 and 2.5 years, respectively ( $\mathrm{HR}=0.4, \mathrm{P}=0.0467)$ ] (34). Ultimately, oncologic outcomes are inextricably linked to disease stage.

\section{Screening and stage of presentation}

The evolution of current screening guidelines has led to a markedly improved CRC mortality rate by increasing detection of early stage malignancy (3). Unfortunately, disparities in screening and stage at presentation still exist and likely contribute to disparities in outcomes of CRC. A study by Ahmed et al. using data collected from 5,900 adults eligible for endoscopic screening for CRC from the National Health Interview Survey showed that compared with Caucasians, Hispanic are $34 \%(\mathrm{P}<0.01)$ and Black patients are 26\% $(\mathrm{P}<0.05)$ less likely to receive a recommendation for CRC screening from providers (35). A similar study conducted using the SEER database showed Black patients are less likely than non-Black patients to have undergone CRC screening ( $75 \%$ vs. $82 \%, \mathrm{P}=0.001)$, and were also less likely to be up-to-date with CRC screening (66\% vs. $72 \%, \mathrm{P}=0.001$ ) (36). Furthermore, these disparities have been shown to exist even in Asian populations with studies showing that Filipinos (OR 0.56), Chinese (OR 0.70 ), and Hawaiians (OR 0.75 ) were significantly less likely than Whites to undergo CRC screening when recommended (34).

Mechanisms expanding upon screening disparities are multifactorial. A lack of explicit recommendations regarding screening from providers has shown to contribute to decreased screening rates in Hispanic patients compared to White patients $(35,37)$. Furthermore, it has been shown that patient's perceived screening barriers, lack of awareness and a lack of provider communication about CRC screening options may contribute to low screening rates among minority populations (37). Several studies suggest that SES and access to health care may explain all major racial/ethnic disparities in CRC screening recommendation rates and screening compliance $(34,35)$.

Residential segregation and distance to travel have also been identified as barriers to appropriate screening. For example, patients in areas with the largest capacity for CRC screening were more likely to receive a colonoscopy than those in areas with the greatest percentage of Black patients (38). Distance and access to screening programs also explains disparities that exist among rural populations $(39,40)$. Carmichael et al. sought to assess adherence to recommended screening guidelines via a publicly available surveillance system and correlating screening participation with county CRC mortality from the National Cancer Institute (41). The authors found that states with the highest screening rates had the smallest urban-rural disparities, while those with the lowest screening rates had the largest disparities (41). Finally, they found that rural counties experienced $\sim 5$ more deaths per 100,000 population even after controlling for screening rates (41). Insurance status is another contributing disparity with a study showing that survival was greater for patients with insurance other than Medicaid for all races, but the differential in survival varied with race (42).

In addition to screening disparities, studies have revealed disparities in stage at presentation. One such populationbased study conducted using the SEER database between 
2007 and 2014 analyzed the impact of patient age, race, primary, site, state/county, and insurance status on cancer staging at diagnosis. This study found sociodemographic risk factors associated with a higher stage at diagnosis include low income, race/ethnicity, age, and gender (43). A smaller scale study, conducted at an urban-safety net hospital found that Black patients are nearly four times as likely to have stage III-IV CRC at diagnosis compared to Whites $(\mathrm{P}=0.055)$, thereby increasing the risk for cancer recurrence and mortality and further substantiating these findings in diverse care settings (44). Robbins et al. identified that the disparity in late-stage mortality accounted for approximately $60 \%$ of the overall Black-White mortality disparity in CRC, and concluded that concerted efforts to prevent or detect CRC at earlier stages in Black patients could improve observed racially driven disparities (33).

\section{Treatment}

Treatment differences in vulnerable populations in addition to poor access to screening and provider driven education likely contribute to survival and morbidity disparities. A retrospective study by Laryea $e t a l$. found no difference in overall survival or cancer specific mortality between Whites and Blacks in a study where Blacks and Whites were treated identically. This may indicate that provider centered treatment may be significantly contributing to poorer outcomes for Black patients (45). Despite this, Tramontano et al. found that after controlling for patient and clinical characteristics, NHB were less likely to receive treatment but were more likely to have higher cancer-attributable costs within different phases of care (46). Finally, differences in the extent of surgical resection, namely sphincter preservation in rectal cancer treatment is also evident. In a single institution study with a cancer center and a safety-net affiliate, sphincter preservation was less likely for those with the lowest quartile of income (32). In a separate population based study using the nationwide inpatient sample (NWIS), both Black patients and Medicaid insured patients were less likely to undergo sphincter preservation than White and privately insured patients (47). This may reflect less use of sphincter preserving perioperative therapy, patient misperception of disease process, or a lack of physician led communication and education.

\section{Prostate cancer}

The incidence and mortality of prostate cancer in Black men in the United States is disproportionately high (48). There are several hypotheses regarding both biologic and sociodemographic risks that are potentially unique to Black men compared to White men $(49,50)$. While the total incidence of prostate cancer has declined in recent years, the rate of metastatic prostate cancer remains high among Black Americans $(1,51,52)$. Additionally, patients with low relative income, those from disadvantaged neighborhoods, and those with limited social support have experienced disparate prostate cancer specific care including screening, diagnosis at an intervenable stage, and therapy (49,51-74). These risks have come into sharper focus as guidelines for screening men for prostate cancer have shifted over time. The use of prostate specific antigen (PSA) screening and early screening are now largely dependent upon shared decision making on the part of providers and patients. Table 3 summarizes the following sections in outcomes, screening, and treatment disparities in prostate cancer care.

\section{Outcomes disparities}

Several studies have outlined differences in survival in vulnerable populations defined by multiple independent sociodemographic risk factors. Disparities in prostate cancer specific survival in Black men compared to White men have been demonstrated in both retrospective nationwide and statewide observational database driven studies as well as using predictive modeling from institutional data $(51,52,54-$ $56,61,64,65,72)$. Compared to NHW men, Black men carried up to $60 \%$ higher risk of mortality (56). Additional data from the California Cancer Registry attempting to identify prognostic sociodemographic risk factors suggests that Hispanic immigrants at a prostate cancer specific mortality that was $20 \%$ greater than that of NHWs (54).

A separate study from a statewide database in California revealed that men from disadvantaged neighborhoods as determined by census income, education, and occupation data have a higher risk of mortality from prostate cancer (70). While both race and SES have been shown to be risk factors for mortality in the United States, these factors are difficulty to distinguish as independent risk factors. Interestingly, low SES has also been shown to have almost a $20 \%$ increased incidence of mortality in a Swedish population based study examining a relatively homogenous population with a nationalized health plan (73). A common theme amongst high risk sociodemographic groups is that these patients tend to present at a later stage compared to their lower risk counterparts and often undergo less aggressive therapies 
Table 3 A summary of studies examining disparities in screening, delivery, and outcomes in prostate cancer care

\begin{tabular}{|c|c|c|c|c|c|}
\hline Study focus & Journal & Author and year & $\mathrm{N}$ & Study type & Summary \\
\hline \multirow{3}{*}{ Outcome } & Cancer & $\begin{array}{l}\text { Schupp } \\
\text { et al. } 2014\end{array}$ & 35,427 & $\begin{array}{l}\text { Retrospective } \\
\text { observational study } \\
\text { using a state registry }\end{array}$ & $\begin{array}{l}\text { - Survival among Hispanic US-born men with prostate } \\
\text { cancer who live in communities with a high density } \\
\text { of Hispanic inhabitants is worse than Foreign-born } \\
\text { Hispanic men in high density neighborhood and worse } \\
\text { than US or Foreign-born men in low density Hispanic } \\
\text { neighborhoods [HR 0.84; } 95 \% \mathrm{Cl}:(0.78-0.9)]\end{array}$ \\
\hline & $\begin{array}{l}\text { JAMA } \\
\text { Network } \\
\text { Open Urology }\end{array}$ & $\begin{array}{l}\text { Fletcher } \\
\text { et al. } 2020\end{array}$ & 229,771 & $\begin{array}{l}\text { Retrospective } \\
\text { observational study } \\
\text { using national } \\
\text { database }\end{array}$ & $\begin{array}{l}\text { - Nearly } 25 \% \text { of analyzed state cancer registries } \\
\text { showed a higher prostate cancer specific mortality in } \\
\text { Black men compared to White men with low grade } \\
\text { disease }\end{array}$ \\
\hline & Cancer & $\begin{array}{l}\text { Aizer } \\
\text { et al. } 2014\end{array}$ & $1,001,978$ & $\begin{array}{l}\text { Retrospective } \\
\text { observational study } \\
\text { using national } \\
\text { database }\end{array}$ & $\begin{array}{l}\text { - Black men had a worse cancer specific mortality after } \\
\text { adjusting for stage and sociodemographic factors } \\
\text { compared to white men [HR 1.36, 95\% Cl: (1.27- } \\
1.46)]\end{array}$ \\
\hline \multirow[t]{3}{*}{$\begin{array}{l}\text { Screening \& } \\
\text { presentation }\end{array}$} & $\begin{array}{l}\text { J Natl Med } \\
\text { Assoc }\end{array}$ & $\begin{array}{l}\text { Percy-Laurry } \\
\text { et al. } 2018\end{array}$ & 945 & $\begin{array}{l}\text { Retrospective } \\
\text { observational study } \\
\text { using national } \\
\text { database }\end{array}$ & $\begin{array}{l}\text { - Black men with a high school level education were } \\
\text { more likely to present with high-grade tumors than } \\
\text { Black men with higher degrees of education [1.73; } \\
95 \% \mathrm{Cl}:(1.11-2.71)]\end{array}$ \\
\hline & $\begin{array}{l}J \text { Racial Ethn } \\
\text { Health }\end{array}$ & $\begin{array}{l}\text { Ogunsanya } \\
\text { et al. } 2017\end{array}$ & 267 & $\begin{array}{l}\text { Cross-sectional survey } \\
\text { study }\end{array}$ & $\begin{array}{l}\text { - Black men with private }(\mathrm{OR}=1.5 ; 95 \% \mathrm{Cl}: 1.37-2.18 \\
\mathrm{P}<0.05) \text { or public insurance }(\mathrm{OR}=1.45 ; 95 \% \mathrm{Cl}: 1.29- \\
3.18 ; \mathrm{P}<0.01) \text { were more likely than uninsured men } \\
\text { to plan to get screened. Black men with a regular } \\
\text { source of care }(\mathrm{OR}=2.61 ; 95 \% \mathrm{Cl}: 1.1-1.96 ; \mathrm{P}<0.05) \\
\text { were more likely to undergo screening }\end{array}$ \\
\hline & J Urology & $\begin{array}{l}\text { Krishna } \\
\text { et al. } 2016\end{array}$ & 13,374 & $\begin{array}{l}\text { Retrospective } \\
\text { observational study } \\
\text { using national } \\
\text { database }\end{array}$ & $\begin{array}{l}\text { - A greater proportion of Black men (58\%) did not } \\
\text { undergo any surveillance strategy compared to White } \\
\text { men ( } 37 \%) \\
\text { - The likelihood of active surveillance among Black } \\
\text { men was significantly lower (OR } 0.4,95 \% \mathrm{Cl} \text { : } 0.17 \text { - } \\
0.95 ; \mathrm{P}=0.039 \text { ) than White men }\end{array}$ \\
\hline
\end{tabular}

Table 3 (continued) 
Table 3 (continued)

\begin{tabular}{|c|c|c|c|c|c|}
\hline Study focus & Journal & Author and year & $\mathrm{N}$ & Study type & Summary \\
\hline \multirow{7}{*}{ Treatment } & & & & & $\begin{array}{l}\text { - Among men receiving definitive therapy, Black } \\
\text { men were less likely than White to receive radical } \\
\text { prostatectomy [OR } 0.71 ; 95 \% \mathrm{Cl}(0.52-0.98)]\end{array}$ \\
\hline & Cancer & $\begin{array}{l}\text { Mahal } \\
\text { et al. } 2018\end{array}$ & 155,524 & $\begin{array}{l}\text { Retrospective } \\
\text { observational study }\end{array}$ & $\begin{array}{l}\text { - Black men more likely than White to present with } \\
\text { metastatic disease [aOR } 1.07(1.01-1.13) ; P=0.015]\end{array}$ \\
\hline & & & & $\begin{array}{l}\text { using national } \\
\text { database }\end{array}$ & $\begin{array}{l}\text { - Medicaid [aOR } 4.27(4.01-4.55) ; \mathrm{P}<0.001] \text { and } \\
\text { Uninsured [aOR } 4.12(3.8-4.48) ; \mathrm{P}<0.001] \text { more } \\
\text { likely than privately insured patients to present with } \\
\text { metastatic disease }\end{array}$ \\
\hline & & & & & $\begin{array}{l}\text { - Medicaid [aOR } 0.67(0.62-0.71) ; \mathrm{P}<0.001] \text { and } \\
\text { Uninsured [aOR } 0.48(0.44-0.52) ; \mathrm{P}<0.001 \text { ] less likely } \\
\text { than privately insured men to undergo definitive } \\
\text { therapy }\end{array}$ \\
\hline & & & & & $\begin{array}{l}\text { - Prostate cancer specific mortality more likely in } \\
\text { Medicaid [aHR 1.83 (1.5-2.24); } \mathrm{P}<0.001] \text {, Uninsured } \\
\text { [aHR 1.80 (1.4-2.31); } \mathrm{P}<0.001] \text { than privately insured } \\
\text { patients and in Black men [1.16 (1.01-1.33); } \mathrm{P}=0.038] \\
\text { than White men }\end{array}$ \\
\hline & $\begin{array}{l}\text { Cancer Caus } \\
\& \text { Control }\end{array}$ & sLee et al. 2018 & 604 & $\begin{array}{l}\text { Observational } \\
\text { retrospective analysis } \\
\text { of prospectively } \\
\text { collected database }\end{array}$ & $\begin{array}{l}\text { - Black }(45 \%) \text { and Hispanic }(56 \%) \text { men with low risk } \\
\text { prostate cancer received external beam radiation } \\
\text { therapy that met all quality metrics compared to } 75 \% \\
\text { of White men }(\mathrm{P}=0.007)\end{array}$ \\
\hline & Cancer & $\begin{array}{l}\text { Gordon et al. } \\
2019\end{array}$ & 1,170 & $\begin{array}{l}\text { Observational study } \\
\text { survey of Black } \\
\text { men from statewide } \\
\text { prostate cancer } \\
\text { survivorship registry }\end{array}$ & $\begin{array}{l}\text { - A greater percentage of Black men did not perceive } \\
\text { high risk cancers as aggressive cancers compared } \\
\text { to White men ( } 53.9 \% \text { vs. } 24.0 \% ; \mathrm{P}<0.001) \text { though } \\
\text { this was not associated with a difference in receipt of } \\
\text { therapy }\end{array}$ \\
\hline
\end{tabular}

$(48,55,60,69,73,75)$.

\section{Screening, stage of presentation, and surveillance}

The methodology and nature of screening in prostate cancer has evolved significantly over the past decade. In
2012, the USPSTF formally recommended against PSA screening based on analysis of the Prostate Lung Colorectal and Ovarian cancer dataset in which only $4 \%$ of the studied population were of Black race (65). Furthermore, concomitant studies demonstrated that Black men presented more often with more aggressive, advanced disease (48). 
Since then, the USPSTF and American Urological Association have published screening recommendations for the early detection of prostate cancer that are essentially predicated upon shared decision making between providers and patients $(76,77)$. Using the SEER database, Mahal et al. demonstrated not only that Black men had a $7 \%$ higher chance of presenting with metastatic disease than White men, but that the odds of presenting with metastatic disease was over four times higher in Medicaid-insured and uninsured populations compared to those with private insurance (65). A study using the Pennsylvania state cancer registry identified impoverished and immigrant populations based on US census data as variables that were associated with late stage at presentation (78). The study also indicated that a lack of social support was associated with late stage at presentation, which has been shown in other studies as well as single men more often presented with metastatic disease than married men (52).

Surveillance of disease for patients with prostate cancer who are not undergoing active therapy can vary in the degree of aggressiveness. The extent to which patients undergo active surveillance compared with expectant management is again a shared decision between patient and provider and can lead to earlier institution of therapy when indicated $(59,60)$. Krishna et al. showed in a study of the SEER database that Black men are less likely to participate in active surveillance comprised of serial PSA, frequent biopsies, and semiannual history and physical exams (62).

Perhaps the most important factor in the pathway of prostate care for men from vulnerable populations is the relationship with a primary care provider. Given the risk of developing cancer that is associated with Black race, there must regular discussions between patients and physicians regarding the benefits and harms of prostate cancer screening and subsequent treatment. The risk of overdiagnosis and overtreatment should seriously be considered given data suggesting that up to $50 \%$ of men are overdiagnosed, biopsy alone carries a $2-5 \%$ risk of complication, and definitive treatment exposes $20 \%$ of patients or more to significant morbidity $(77,79,80)$. The risk of overdiagnosis and treatment is further highlighted by data emphasizing the importance of quality of life particularly in Black men compared to White men (59). Communication between primary care physicians and patients from disadvantaged populations must be strengthened, given the evidence suggesting that there is a discordance between patient perception and the nature of their diagnosis (59).

\section{Treatment}

Krishna et al. highlighted differences in active surveillance for Black men with low risk prostate cancer compared White men (62). This is in concordance with studies that have shown that Black men present with higher stage and grade disease. Notably, several authors have demonstrated that Black and Hispanic men are less likely than White men to receive definitive therapy, including radical prostatectomy, external beam radiation, and brachytherapy (63). While population-based studies have generally suggested that fewer treatment options are both presented to and administered for minority patients, there is a paucity of studies that attempt to ascertain the perception of such interactions from the standpoint of the patient. Gordon $e t a l$. assessed the perceptions of Black men regarding their diagnoses and summarized their priorities with respect to cancer treatment (59). The focus of both Black and White men who perceived their cancers as aggressive was curing their disease. Black men who perceived that they had less aggressive disease placed much more importance on the cost of care, time to recovery, and impact on daily life (59). Most importantly, the study highlighted that significantly more Black men perceived their cancers to be less aggressive than they truly were, and in turn were less likely to receive definitive therapy compared to patients who perceived having more aggressive cancers (59).

\section{Future direction}

Given the multitude of barriers to care that exist for vulnerable populations, it is important to study how providers have both succeeded and failed in mitigating them. Studies that have quantified the impact of Medicaid expansion have shown that survival outcomes between now-Medicaid insured and privately insured patients are not nearly equivalent, but at the very least Medicaid insured patients had improved survival relative to uninsured patients (14). Other approaches that have been successful include culturally tailored education and navigation services which may be effective in reducing these disparities and financial incentives to decrease screening disparities among some sociodemographically disadvantaged groups $(34,81)$.

Intuitively, the approach to sociodemographic healthcare disparities must be similar to the concept of precision medicine-targeted and synergistic. To reduce these disparities, community resources including education, outreach, prevention, and screening must be strengthened, 
and aid in navigating the healthcare system once a diagnosis is made should be provided. Recent data strengthening the association between residential segregation, rural locations, and distance to travel for care and screening, treatment, and outcomes in cancer care has given us a starting point to for outreach $(39,40,69,82-86)$. Relationships between surgeons, oncologists, and primary care providers who care for patients in these regions must be strengthened such that there is a common and up-to-date understanding of solid tumor screening guidelines. Referral pipelines to facilities that can either provide or coordinate definitive, multimodal therapy must be created with attention to anticipated patient care needs and potential difficulties with insurance coverage. Such models of partnership are already being built, and frameworks for the creation of such community outreach programs are available (87).

Lung cancer remains the most lethal and among the most commonly diagnosed cancers in the United States, along with breast, colorectal, and prostate cancer. Like breast, colorectal, and prostate cancer, lung cancer shares common disparities in screening, treatment, and outcomes and likely shares similar solutions (88-94). Similar to the progression of screening recommendations in breast and prostate cancer, the recommendation to screen patients for lung cancer will evolve as we are better able to quantify the risk conferred by demographic factors alone as well as the risks associated with consequent procedures for diagnosis and treatment. The adoption of safe, lung sparing, minimally invasive resections for early-stage disease may also significantly influence our recommendations to patients and referring physicians. This data will allow primary care providers, pulmonologists, and thoracic surgeons to engage in informative conversations and shared decision making.

\section{Acknowledgments}

Funding: None.

\section{Footnote}

Provenance and Peer Review: This article was commissioned by the Guest Editors (Virginia Litle and Kei Suzuki) for the series "Socioeconomic Disparities in the Treatment of Thoracic Malignancies" published in Fournal of Thoracic Disease. The article has undergone external peer review.

Reporting Checklist: The authors have completed the Narrative Review reporting checklist. Available at: http:// dx.doi.org/10.21037/jtd-21-87

Peer Review File: Available at http://dx.doi.org/10.21037/jtd21-87

Conflicts of Interest: Both authors have completed the ICMJE uniform disclosure form (available at http://dx.doi. org/10.21037/jtd-21-87). The series "Socioeconomic Disparities in the Treatment of Thoracic Malignancies" was commissioned by the editorial office without any funding or sponsorship. The authors have no other conflicts of interest to declare.

Ethical Statement: The authors are accountable for all aspects of the work in ensuring that questions related to the accuracy or integrity of any part of the work are appropriately investigated and resolved.

Open Access Statement: This is an Open Access article distributed in accordance with the Creative Commons Attribution-NonCommercial-NoDerivs 4.0 International License (CC BY-NC-ND 4.0), which permits the noncommercial replication and distribution of the article with the strict proviso that no changes or edits are made and the original work is properly cited (including links to both the formal publication through the relevant DOI and the license). See: https://creativecommons.org/licenses/by-nc-nd/4.0/.

\section{References}

1. Siegel RL, Miller KD, Jemal A. Cancer statistics, 2020. CA Cancer J Clin 2020;70:7-30.

2. DeSantis CE, Ma J, Sauer AG, et al. Breast cancer statistics, 2017, racial disparity in mortality by state. CA Cancer J Clin 2017;67:439-48.

3. Kuipers EJ, Grady W, Lieberman D, et al. Colorectal Cancer. Nat Rev Dis Prim 2015;1:15065.

4. Litwin MS, Tan HJ. The diagnosis and treatment of prostate cancer: A review. JAMA 2017;317:2532-42.

5. Siegel RL, Miller KD, Jemal A. Cancer statistics, 2018. CA Cancer J Clin 2018;68:7-30.

6. Siegel RL, Miller KD, Jemal A. Cancer statistics, 2019. CA Cancer J Clin 2019;69:7-34.

7. McGuire A, Brown J, Malone C, et al. Effects of age on the detection and management of breast cancer. Cancers (Basel) 2015;7:908-29.

8. Balasubramanian R, Rolph R, Morgan C, et al. Genetics of breast cancer: management strategies and risk-reducing 
surgery. Br J Hosp Med (Lond) 2019;80:720-5.

9. Siu AL; U.S. Preventive Services Task Force.

Screening for Breast Cancer: US Preventive Task Force Recommendation Statement. Ann Intern Med 2016;164:279-96.

10. Harbeck N, Gnant M. Breast Cancer. Lancet 2017;389:1134-50.

11. Newman LA. Breast cancer disparities: socioeconomic factors versus biology. Ann Surg Oncol 2017;24:2869-75.

12. Mets EJ, Chouairi FK, Gabrick KS, et al. Persistent disparities in breast cancer surgical outcomes among Hispanic and African American patients. Eur J Surg Oncol 2019;45:584-90.

13. Semprini J, Olopade O. Evaluating the effect of Medicaid expansion on black/white breast cancer mortality disparities: a difference-in-difference analysis. JCO Glob Oncol 2020;6:1178-83.

14. Abdelsattar ZM, Hendren S, Wong SL. The Impact of Health Insurance on Cancer Care in Disadvantaged Comunities. Cancer 2017;123:1219-27.

15. Nahleh Z, Otoukesh S, Mirshahidi HR, et al. Disparities in breast cancer: A multi-institutional comparative analysis focusing on American Hispanics. Cancer Med 2018;7:2710-7.

16. Tin Tin S, Elwood J, et al. Ethnic disparities in breast cancer survival in New Zealand: which factors contribute? BMC Cancer 2018;18:58.

17. Silber JH, Rosenbaum PR, Ross RN, et al. Disparities in Breast Cancer Survival by Socioeconomic Status Despite Medicare and Medicaid Insurance. Milbank Q 2018;96:706-54.

18. Balazy KE, Benitez CM, Gutkin PM, et al. Association between primary language, a lack of mammographic screening, and later stage breast cancer presentation. Cancer 2019;125:2057-65.

19. Parikh DA, Chudasama R, Agarwal A, et al. Race/ Ethnicity, Primary Language, and Income Are Not Demographic Drivers of Mortality in Breast Cancer Patients at a Diverse Safety Net Academic Medical Center. Int J Breast Cancer 2015;2015:835074.

20. Jones BA, Patterson EA, Calvocoressi L. Mammography screening in African American women: Evaluating the research. Cancer 2003;97:258-72.

21. Newman LA, Kaljee LM. Health disparities and triplenegative breast cancer in African American women: a review. JAMA Surg 2017;152:485-93.

22. Hirth JM, Laz TH, Rahman M, et al. Racial/Ethnic differences affecting adherence to cancer screening guidelines among women. J Womens Health (Larchmt) 2016;25:371-80.

23. Simianu VV, Morris AM, Varghese TKJ, et al. Evaluating disparities in inpatient surgical cancer care among American Indian/Alaska Native patients. Am J Surg 2016;212:297-304.

24. Hoppe EJ, Hussain LR, Grannan KJ, et al. Racial disparities in breast cancer persist despite early detection: analysis of treatment of stage I breast cancer and effect of insurance status on disparities. Breast Cancer Res Treat 2019;173:597-602.

25. Lautner M, Lin H, Shen Y, et al. Disparities in the use of breast-conserving therapy among patients with early-stage breast cancer. JAMA Surg 2015;150:778-86.

26. Akinyemiju T, Sakhuja S, Vin Raviv N. Racial and SocioEconomic Disparities in Breast Cancer Hospitalization Outcomes by Insurance Status. Cancer Epidemiol 2016;43:63-9.

27. Dreyer MS, Nattinger AB, McGinley EL, et al. Socioeconomic status and breast cancer treatment. Breast Cancer Res Treat 2018;167:1-8.

28. Colorectal Cancer Statistics. Center for Disease Control and Prevention 2020.

29. Bibbins-Domingo K, Grossman DC, Curry SJ, et al. Screening for colorectal cancer: US preventive services task force recommendation statement. JAMA 2016;315:2564-75.

30. Le H, Ziogas A, Lipkin SM, et al. Effects of socioeconomic status and treatmet disparities in colorectal cancer survival. Cancer Epidemiol Biomarkers Prev 2008;17:1950-62.

31. White A, Vernon SW, Franzini L, et al. Racial disparities in colorectal cancer survival: To what extent are racial disparities explained by differences in treatment, tumor characteristics, or hospital characteristics? Cancer 2010;116:4622-31.

32. Nitzkorski JR, Willis AI, Nick D, et al. Association of race and socioeconomic status and outcomes of patients with rectal cancer. Ann Surg Oncol 2013;20:1142-7.

33. Robbins AS, Siegel RL, Jemal A. Racial disparities in stage-specific colorectal cancer mortality rates from 1985 to 2008. J Clin Oncol 2012;30:401-5.

34. Domingo JB, Chen JJ, Braun KL. Colorectal Cancer Screening Compliance among Asian and Pacific Islander Americans. J Immigr Minor Health 2018;20:584-93.

35. Ahmed NU, Pelletier V, Winter K, et al. Factors explaining racial/ethnic disparities in rates of physician recommendation for colorectal cancer screening. Am J Public Health 2013;103:e91-9.

36. Mobley LR, Kuo TM. Demographic disparities in late- 
stage diagnosis of breast and colorectal cancers across the USA. J Racial Ethn Health Disparities 2017;4:201-12.

37. Nagelhout E, Comarell K, Samadder NJ, et al. Barriers to Colorectal Cancer Screening in a Racially Diverse Population Served by a Safety-Net Clinic. J Community Health 2017;42:791-6.

38. Brawarsky P, Neville BA, Fitzmaurice GM, et al. Surveillance after resection for colorectal cancer. Cancer 2013;119:1235-42.

39. Wang H, Roy S, Kim J, et al. Barriers of colorectal cancer screening in rural USA: A systematic review. Rural Remote Health 2019;19:5181.

40. Alyabsi M, Meza J, Islam KMM, et al. Colorectal cancer screening uptake: differences between rural and urban privately-insured population. Front Public Health 2020;8:532950.

41. Carmichael H, Cowan M, McIntyre R, et al. Disparities in colorectal cancer mortality for rural populations in the United States: Does screening matter? Am J Surg 2020;219:988-92.

42. Pulte D, Jansen L, Brenner H. Social disparities in survival after diagnosis with colorectal cancer: Contribution of race and insurance status. Cancer Epidemiol 2017;48:41-7.

43. Patel A, Gantz O, Zagadailov P, et al. The role of socioeconomic disparity in colorectal cancer stage at presentation. Updates Surg 2019;71:523-31.

44. Chan C, Lopez A, Castaneda G, et al. Black Patients with Colorectal Cancer Have More Advanced Cancer Stage at Time of Diagnosis: A Community-Based Safety-Net Hospital Experience. J Community Health 2017;42:724-9.

45. Laryea JA, Siegel E, Klimberg S. Racial disparity in colorectal cancer: The role of equal treatment. Dis Colon Rectum 2014;57:295-302.

46. Tramontano AC, Chen Y, Watson TR, et al. Racial/ ethnic disparities in colorectal cancer treatment utilization and phase-specific costs, 2000-2014. PLoS One 2020;15:e0231599.

47. Arsoniadis EG, Fan Y, Jarosek S, et al. Decreased Use of Sphincter-Preserving Procedures Among African Americans with Rectal Cancer. Ann Surg Oncol 2018;25:720-8.

48. McGinley KF, Tay KJ, Moul JW. Prostate cancer in men of African origin. Nat Rev Urol 2016;13:99-107.

49. Bhardwaj A, Srivastava SK, Khan MA, et al. Racial disparities in prostate cancer: A molecular perspective. Front Biosci (Landmark Ed) 2017;22:772-82.

50. Kumar S, Singh R, Malik S, et al. Prostate cancer health disparities: An immuno-biological perspective. Cancer
Lett 2018;414:153-65.

51. Badal S, Aiken W, Morrison B, et al. Disparities in prostate cancer incidence and mortality rates: Solvable or not? Prostate 2020;80:3-16.

52. Aizer AA, Wilhite TJ, Chen MH, et al. Lack of reduction in racial disparities in cancer-specific mortality over a 20year period. Cancer 2014;120:1532-9.

53. Brown CR, Hambleton I, Hercules SM, et al. Social determinants of prostate cancer in the Caribbean: A systematic review and meta-analysis. BMC Public Health 2018;18:900.

54. Chen SL, Wang SC, Ho CJ, et al. Prostate cancer mortality-to-incidence ratios are associated with cancer care disparities in 35 countries. Sci Rep 2017;7:40003.

55. Coughlin SS. A review of social determinants of prostate cancer risk, stage, and survival. Prostate Int 2020;8:49-54.

56. Ellis L, Canchola AJ, Spiegel D, et al. Racial and ethnic disparities in cancer survival: The contribution of tumor, sociodemographic, institutional, and neighborhood characteristics. J Clin Oncol 2018;36:25-33.

57. Ellis L, Canchola AJ, Spiegel D, et al. Trends in cancer survival by health insurance status in California from 1997 to 2014. JAMA Oncol 2018;4:317-23.

58. Fletcher SA, Marchese M, Cole AP, et al. Geographic Distribution of Racial Differences in Prostate Cancer Mortality. JAMA Netw Open 2020;3:e201839.

59. Gordon BE, Basak R, Carpenter WR, et al. Factors influencing prostate cancer treatment decisions for African American and white men. Cancer 2019;125:1693-700.

60. Jiang S, Narayan V, Warlick C. Racial disparities and considerations for active surveillance of prostate cancer. Transl Androl Urol 2018;7:214-20.

61. Kaur D, Ulloa-Pérez E, Gulati R, et al. Racial disparities in prostate cancer survival in a screened population: Reality versus artifact. Cancer 2018;124:1752-9.

62. Krishna S, Fan Y, Jarosek S, et al. Racial disparities in active surveillance for prostate cancer. J Urol 2017;197:342-9.

63. Lee DJ, Zhao Z, Huang LC, et al. Racial variation in receipt of quality radiation therapy for prostate cancer. Cancer Causes Control 2018;29:895-9.

64. Mahal AR, Mahal BA, Nguyen PL, et al. Prostate cancer outcomes for men aged younger than 65 years with Medicaid versus private insurance. Cancer 2018;124:752-9.

65. Mahal BA, Chen YW, Muralidhar V, et al. Racial disparities in prostate cancer outcome among prostatespecific antigen screening eligible populations in the United States. Ann Oncol 2017;28:1098-104. 
66. Ogunsanya ME, Brown CM, Odedina FT, et al. Determinants of Prostate Cancer Screening Intentions of Young Black Men Aged 18 to 40 Years. J Racial Ethn Health Disparities 2016. [Epub ahead of print]. doi: 10.1007/s40615-016-0305-1. Erratum in: J Racial Ethn Health Disparities 2017;4:1021.

67. Owens OL, Kim S, Tavakoli AS. Are decision aids leading to shared prostate cancer screening decisions among African-American men?: iDecide. Cancer Causes Control 2019;30:713-9.

68. Percy-Laurry A, Alterkruse SF, Hossain MB, et al. Association between socioeconomic status and tumor grade among black men with prostate cancer. J Natl Med Assoc 2018;110:53-7.

69. Poulson MR, Helrich SA, Kenzik KM, et al. The impact of racial residential segregation on prostate cancer diagnosis and treatment. BJU Int 2021;127:636-44.

70. Schupp CW, Press DJ, Gomez SL. Immigration factors and prostate cancer survival among Hispanic men in California: Does neighborhood matter? Cancer 2014;120:1401-8.

71. Watson M, Grande D, Radhakrishnan A, et al. Racial differences in prostate cancer treatment: the role of socioeconomic status. Ethn Dis 2017;27:201-8.

72. Wang C, Kamrava M, King C, et al. Racial disparity in prostate cancer-specific mortality for high-risk prostate cancer: a population-based study. Cureus 2017;9:e961.

73. Tomic K, Ventimiglia E, Robinson D, et al. Socioeconomic status and diagnosis, treatment, and mortality in men with prostate cancer. Nationwide population-based study. Int J Cancer 2018;142:2478-84.

74. Stern MC, Fejerman L, Das R, et al. Variability in Cancer Risk and Outcomes Within US Latinos by National Origin and Genetic Ancestry. Curr Epidemiol Rep 2016;3:181-90.

75. Kelly SP, Anderson WF, Rosenberg PS, et al. Past, Current, and Future Incidence Rates and Burden of Metastatic Prostate Cancer in the United States. Eur Urol Focus 2018;4:121-7.

76. Carter HB, Albertsen PC, Barry MJ, et al. Early detection of prostate cancer: AUA guideline. J Urol 2013;190:419-26.

77. Grossman DC, Curry SJ, Owens DK, et al. Screening for prostate cancer US Preventive services task force recommendation statement. JAMA 2018;319:1901-13.

78. Lynch SM, Mitra N, Ross M, et al. A NeighborhoodWide Association Study (NWAS): Example of prostate cancer aggressiveness. PLoS One 2017;12:e0174548.

79. Miller AB. New data on prostate-cancer mortality after PSA screening. N Engl J Med 2012;366:1047-8.
80. Moyer VA. Screening for prostate cancer: U.S. preventive services task force recommendation statement. Ann Intern Med 2012;157:120-34.

81. Haddad JD, You DM. Colorectal Cancer Screening and Race in an Equal Access Medical System. J Community Health 2016;41:78-81.

82. Poulson MR, Beaulieu-Jones BR, Kenzik KM, et al. Residential Racial Segregation and Disparities in Breast Cancer Presentation, Treatment, and Survival. Ann Surg 2021;273:3-9.

83. Poulson M, Cornell E, Madiedo A, et al. The impact of racial residential segregation on colorectal cancer outcomes and treatment. Ann Surg 2021;273:1023-30.

84. Holmes JA, Carpenter WR, Wu Y, et al. Impact of Distance to a Urologist on Early Diagnosis of Prostate Cancer Among Black and White Patients. J Urol 2012;187:883-8.

85. Jones LA, Ferrans CE, Polite BN, et al. Examining racial disparities in colon cancer clinical delay in the Colon Cancer Patterns of Care in Chicago study. Ann Epidemiol 2017;27:731-738.e1.

86. Vetterlein MW, Löppenberg B, Karabon P, et al. Impact of travel distance to the treatment facility on overall mortality in US patients with prostate cancer. Cancer 2017;123:3241-52.

87. Giachello AL, Watson KS, Stuart M, et al. Communityacademic partnerships to reduce cancer inequities: The chicagoCHEC community engagement core. Prog Community Health Partnersh 2019;13:21-37.

88. Berland LL, Monticciolo DL, Flores EJ, et al.

Relationships between health care disparities and coverage policies for breast, colon, and lung cancer screening. J Am Coll Radiol 2019;16:580-5.

89. Haddad DN, Sandler KL, Henderson LM, et al. Disparities in lung cancer screening: A review. Ann Am Thorac Soc 2020;17:399-405.

90. Rohatgi KW, Marx CM, Lewis-Thames MW, et al. UrbanRural Disparities in Access to Low-Dose Computed Tomography Lung Cancer Screening in Missouri and Illinois. Prev Chronic Dis 2020;17:E140.

91. Huo J, Xu Y, Sheu T, et al. Complication Rates and Downstream Medical Costs Associated with Invasive Diagnostic Procedures for Lung Abnormalities in the Community Setting. JAMA Intern Med 2019;179:324-32.

92. Japuntich SJ, Krieger NH, Salvas AL, et al. Racial Disparities in Lung Cancer Screening: An Exploratory Investigation. J Natl Med Assoc 2018;110:424-7.

93. Rendle KA, Burnett-Hartman AN, Neslund-Dudas 
$\mathrm{C}$, et al. Evaluating lung cancer screening across diverse healthcare systems: A process model from the lung PROSPR consortium. Cancer Prev Res (Phila) 2020;13:129-36.

Cite this article as: Singh S, Sridhar P. A narrative review of sociodemographic risk and disparities in screening, diagnosis, treatment, and outcomes of the most common extrathoracic malignancies in the United States. J Thorac Dis 2021;13(6):38273843. doi: $10.21037 /$ jtd-21-87
94. Slatore CG, Au DH, Gould MK. An official American Thoracic Society systematic review: Insurance status and disparities in lung cancer practices and outcomes. Am J Respir Crit Care Med 2010;182:1195-205. 